\title{
Application of Remote Sensing in Training Geo- spatial Cognitive Abilities of Secondary Students
}

\author{
http://dx.doi.org/10.3991/ijoe.v10i2.3498 \\ L. Wu ${ }^{1}$, H.Y. Liu ${ }^{2}$ and P. Peng ${ }^{3}$ \\ ${ }^{1}$ Anhui Normal University, Wuhu, China \\ 2 Tongcheng High School, Anhui Province, Tongcheng, China \\ ${ }^{3}$ Geological Survey of Anhui Province, Hefei, China
}

\begin{abstract}
The formation and development of geospatial cognitive abilities are an important aspect of training geographic literacy of secondary students, because these abilities have vital significance for solving their own problems related to geography and its study. However, training geospatial cognitive abilities is currently quite weak in our secondary school's geography curriculum. Many secondary students now have low geospatial cognitive abilities. Remote sensing has a lot of advantages over other training in geospatial cognitive abilities. Therefore, how to use remote sensing in training geospatial cognitive abilities of secondary students should be given necessary importance. Based on the partition of essential factors of geospatial cognitive abilities, this study analyzed some advantages and summarized five teaching strategies integrating remote sensing in training geospatial cognitive abilities in our secondary education, which can provide applicable opinions and suggestions for developing geospatial cognitive abilities of secondary students.
\end{abstract}

Index Terms-Remote sensing, geographical teaching, geospatial cognitive ability, secondary student

\section{INTRODUCTION}

Domestic and foreign scholars found that remote sensing can help learners develop their geo-spatial cognitive ability, solve related geographic space problems, and improve the learners' spatial reasoning ability and spatial thinking level [1-4]. Kerski holds the point of view that an effective geographical system education program should pay special attention to the cultivation of the students' spatial cognitive ability to make the learners better understand the concepts such as spatial patterns, spatial associations and spatial relationships, etc. [4]. As to the research and analysis about how the learning environment influences the students' cognitive ability after using remote sensing, a German scholar Hassenpflug [1] thinks that remote sensing can develop the students' visual space thinking ability, including observing our geographic living environment with a wide viewing angle, multi-spectral perspective and multi-temporal perspective. Therefore, as one of the tools for the development of geo-spatial cognitive ability, what are the unique advantages of remote sensing? In terms of geo-spatial cognitive ability-based elements, how do teachers use remote sensing to develop the students' geographic spatial cognitive ability? These are all issues worthy of further exploration.

\section{GeO-SPATIAL COGNITIVE ABILITY AND ITS INTEGRANT PARTS}

Spatial cognitive ability is a fundamental dimension of human intelligence, and also is an important aspect of human cognitive ability development; research on spatial cognitive ability and related concepts and thoughts is an important part of cognitive psychology [5]. Psychologists' research on space cognition is limited to small-scale space, it refers to pictures or the space of small objects, and the matter it concerns is the spatial cognition process. This is opposed to geographic space, which usually refers to the large-scale space, concerning "what", "where", "why" and other spatial problems in the actual geographical environment, featured by distinctive regional characteristics. It is generally believed that geo-spatial cognitive ability is the ability of knowing about one's survival geographical environment on the basis of geo-spatial cognition, including the ability to analyze and understand relevant position, spatial distribution, mutual relations of various things and phenomena therein as well as their changes and regularity, etc. [6].

Geography not only studies the spatial distribution and characteristics of geographical things, but also clarifies the spatial difference and association, and it is also committed to revealing the spatial movement and variation rules of geographical things [7]. Therefore, from the perspective of geographers, spatial orientation in geography not only includes the ability to observe the same object from different perspectives, but more importantly to judge the spatial position of different geographical things and their mutual relationship, as well as the understanding and interpreting the arrangement situation of essential factors in geographic space structure. Geographic space orientation plays a fundamental role in the process of map reading, map analysis and aerial photographs, etc., and it is the starting point to understanding and solving geographic problems. Spatial visualization in geography includes map and profile map drawing, conversion between $2 \mathrm{D}$ graphics and $3 \mathrm{D}$ graphics, conversion between different projection means, and the conversion between language description and visual characterization [8]. Spatial relationships in geography include: spatial distribution, spatial patterns, analysis of the association between the various space phenomena and elements, understanding and using spatial grades, region division, map contrast or superimposition, map splitting, etc. Psychologists focus on spatial orientation and spatial visualization, and ignore spatial relationship analysis, especially distribution, form, constitution and evolution, etc. These are all closely related to spatial 
PAPER

Application of Remote Sensing in Training Geospatial Cognitive Abilities of Secondary Students

activities, but these are all important aspects in geography [9].

In the process of middle school geography education and problem-solving, students often use a variety of maps, profile maps, landscape maps, schema graphs, etc., and construct or operate related mental images by means of those graphs. Therefore, the formation and development of geo-spatial cognitive abilities will affect the students' geography learning and geographic problem solving. The improvement of spatial cognitive ability is helpful to students to think and practice in spatial way, thus making them obtain a more comprehensive and profound understanding of geography class. Thus, we believe that geospatial cognitive ability cultivation by using remote sensing in middle school geography education can reflect the value of modern geography education.

\section{ADVANTEGES OF REMOTE SENSING IN THE} CULTAVITION OF GEO-SPATIAL COGNITIVE ABILITY OF MIDDLE SCHOOL STUDENTS

The concept of space is a unique concept of geography [10], and geo-spatial cognitive ability is a unique geographic ability, as well as a teaching goal of middle school geography. It is of great importance to help students learn geographic knowledge, to comprehend man-land relationships, and to solve geographic problems, etc. But at present, this lacks pertinence on the cultivation of geo-spatial cognitive ability in middle school geography pedagogy, making the teaching result not satisfactory, and students' geo-spatial cognitive ability poor. Therefore, they encounter many learning difficulties, which have created a bottleneck restricting their learning. Studies show that remote sensing has the advantage of cultivating students' geographic spatial ability in many ways [11-13]. Therefore, in middle school geography classroom instruction, how to develop the students' geo-spatial cognitive ability by using the powerful visualization and spatialization characteristics of remote sensing becomes a problem which urgently must be solved in geography teaching. The unique functions of using remote sensing to develop middle school students' geo-spatial cognitive ability specifically manifest in the following two aspects:

\section{A. The geoscience analytic characteristics of remote sensing is helpful to improve the students' spatial analysis ability and reasoning ability}

Remote sensing geoanalysis refers to the remote sensing information processing and analytical models established on the basis of geoscience rules, and is a comprehensive applied technology and theory combining physical means, mathematical methods and geoanalysis, etc. Through the use of remote sensing geoanalysis functions to implement inquiries, especially the processing and analysis of remote sensing information, remote sensing can improve learners' geographic spatial analysis ability and help them obtain effective information which reflects the regional differentiation rule of the earth and the developing process of geoscience [14]. During the interpretation and analysis process of remote sensing images, learners must clearly know analysis signs or spectral characteristics of different surface features or landform characteristics, and they shall determine the spatial relationship between those surface features. This process can improve the students' spatial reasoning and judgment ability.
Remote sensing geoanalysis includes remote sensing information supported by traditional geoscience analysis methods, remote sensing comprehensive geoanalysis combining geoscience auxiliary information and remote sensing information supported by GIS, and intelligent remote sensing information processing and analysis supported by artificial intelligence theory and methods, etc. Basic spatial attributes can be easily expressed by using remote sensing, and the extraction of related geoscience information becomes easier and more accurate. Therefore, geography teaching through use remote sensing enables students to recognize, extract, represent and transmit geographic information, to analyze the geographic spatial characteristics and spatial evolutionary process of different surface features, to understand and explain the generation background of geographic things and phenomena, to know about their innate characters, to hypothesize about development trends in the future, and to put forward spatial decision-making, thus promoting the development of the students' spatial analysis ability and spatial reasoning ability, and therefore improving their ability to solve geospatial problems.

\section{B. The direct-viewing visualization characteristics of remote sensing is helpful to provide students with multiple perspectives for solving spatial problems}

Visualization is an important cognitive behavior, and it is one of human beings' development abilities for mental characterization. Visualization can promote scientific discovery, resulting in faster and more effective solutions of problems. Therefore, in order to maximize visual level and develop visual thinking ability in students, learners should be provided with opportunities to analyze, synthesize and contrast geographic phenomena and processes on the earth with changing and multiple scales and perspectives. Remote sensing enables us to truly and objectively observe broad geographical space and surface features, and know about distribution characteristics as well as the mutual relationship and rules; remote sensing systems have dynamic characterizations, multiple displays, data conversions, virtual reality and other visualization features, all of which enable students to gain different types of perceptual experience, and provide students with different perspectives and ways of problem-solving. Thus remote sensing can become one of the most effective tools to develop the students' spatial thinking and improve their geographic space problem-solving ability. The perspectives to solve problems by using the direct-viewing visualization characteristics of remote sensing mainly include the following aspects:

First, spatial information of surface features can be represented in different perspectives and ways by using direct-viewing visualizations from remote sensing, thus enabling students to focus on different aspects of the problem and improve their spatial ability. Using remote sensing image processing can selectively extract the feature information related to the task and suppress the irrelevant information, thus users can contrast the internal pattern of geographic spaces, making the seemingly fuzzy and irrelevant information mutually associated.

Secondly, different means of characterization can be provided to different data through the direct-viewing visualizations from remote sensing. Remote sensing technology builds a detection network with multi-layer spaces, multi-wave bands and multi-time phases for Earth obser- 
vation, and also provides the five-dimensional information about the Earth's surface in the dimensions of geographic space, spectrum space and time, etc., thus enabling students to observe and analyze problems all from all sides [15]. In addition, remote sensing images are rich in a variety of geospatial information, and various spatial characteristics of surface features are combined together, which enable learners to obtain a higher level of understanding through exploring and studying the geoscience characteristics of different surface features.

Thirdly, three-dimensional visualization technology and animation can simulate the real space three-dimensional terrain by using remote sensing images combined with digital elevation model (DEM), allowing learners to get to know and understand spatial relationships between different geographical things more quickly. Remote sensing images can also provide recently changed data from an area on the earth surface. For example, using remote sensing images of different periods, one can obtain information regarding environmental changes in an area such as mountain landslides, glaciers, fire and urban growth, etc., and simulate it dynamically with the aid of three dimensional animations, which enable learners to truly experience changes in geography.

\section{CASE OF CULTIVATING THE STUDENTS' GeO-} SPATIAL COGNITIVE ABILITY BY USING REMOTE SENSING

In this class, we will study the space and time change characteristics of urban evolutionary processes and land use patterns in Heifei City, the provincial capital of Anhui Province, in the recent 20 years through use of using remote sensing. Also studied will be the relationship between Hefei and various driving influences and influencing factors, and we will go on to discuss the impact of remote sensing applications on students' geo-spatial cognitive ability. Remote sensing image processing in this teaching case is completed by referring to the references [16].

Teaching task 1: use remote sensing to explore the urban expansion and evolutionary process of Hefei City in the recent 20 years, and get to know about the space and time change characteristics of land use pattern of this city.

First, select a data source, and process the remote sensing data by means of remote sensing image processing software. The remote sensing data includes three groups i.e. the data of 1987, TM/ETM+ of 2000 and CBERS of 2006. Other auxiliary materials include the 1:50,000 scale topographic map of Heifei City, the administrative map of Hefei City and other basic graphic documents as well as the socio-economic survey data of Hefei City and the Statistical Yearbook of Hefei City, etc., and use these graphic documents to assist in the implementation of the rectification and classification disposal on the remote sensing materials. Through data preprocessing and image enhancement combining the background basic database of Heifei City and the data in Google Earth, teachers can establish the land use classification interpretation sign of Heifei City, and implement man-machine interactive interpretation on remote sensing images of these three periods, thus forming the land use remote sensing classification interpretation result graphs of these three periods of 1987 , 2000 and 2006 (Fig. 1).

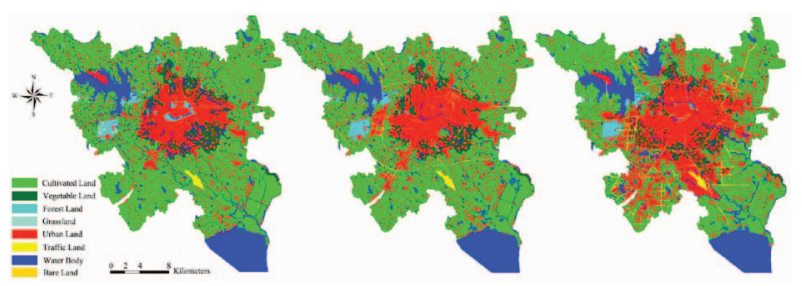

Figure 1. Maps of land use remote sensing classification interpretation result of three periods of 1987 (left), 2000 (middle) and 2006 (right)

During this process, the students shall take the initiative to explore by using remote sensing information. They can contrast the characteristics of urban and town land use area and land use pattern of Hefei City during different periods through observation, and discover space and time changes of urban expansion and evolution processes and land use patterns. At this time, the teacher shall encourage them to think about the reasons and results of the changes they find.

Teaching task 2: use remote sensing to explore the reasons behind urban expansion and evolutionary processes, as well as the space and time changes of land use pattern in Hefei City over the past 20 years.

Guide the students to consider reasons for urban expansion and evolutionary processes, as well as the space and time change of land use patterns in Hefei City over the past 20 years by contrasting remote sensing interpretation images of three periods of 1987, 2000 and 2006. Let the students analyze the relationship between these changes and policies, urbanization progress, population growth and traffic conditions, and to explore the main driving impact factors of these changes. In this process, the students will find that the dramatic changes of land use of Hefei City in the past 20 years mainly manifest as the increasing growth of construction land and continuous decrease in the quantity of arable land. Following this, the teacher can use the measurement function (such as the Measure Areas orders in ERDAS IMAGINE) to calculate the absolute value of change in quantity of different land use types, thus facilitating interpretation and enabling the students to focus on the content and objectives of the curriculum.

Teaching task 3: use remote sensing to explore the impact of the space and time change characteristics of land use pattern in Hefei City, regarding the future urban space development layout.

Display the remote sensing interpretation images of three periods of 1987, 2000 and 2006 in the mode of data superimposition, let the students analyze the impact of changing characteristics of space and time land use patterns on urban development layouts in the future through the superimposition layer. In the exploration process using remote sensing, the teacher shall guide the students consider relationships between space and time change characteristics of land use patterns in the recent 20 years and the urban space development layout in the future, and demand the students to comprehensively summarize the impact of changes in space and time land use pattern characteristics in Hefei City in regards to the urban space development layout of the future. This can further enable the students to summarize and speculate about spatial development patterns of Hefei City, thus cultivating their spatial imagination ability and divergent thinking.

In this class, with the support of the spatial thinking tool remote sensing technology, students' geo-spatial cognitive 
PAPER

Application of Remote Sensing in Training Geospatial Cognitive Abilities of Secondary Students

ability is developed continuously. First, in this process, the students explore and analyze the data independently by themselves through use of remote sensing image processing software, answering questions on the basis of spatial thinking processes, which includes observation, creative discovery, raising questions, proposing answers and discovering these answers, etc.. Thus, the students get the opportunity to independently inquiry and conclude, experience the learning process, rather than passively accept and quote information. The teachers do not provide a "model answer" either, thus promoting the development of geographic spatial thinking. Secondly, use of remote sensing in geography teaching focuses more attention on descriptions and interpretations of geospatial patterns, as well as the reasoning and characterization of geographic spatial relationships. This in turn leads students seek a wide range of interpretations, deepening and developing spatial knowledge and spatial cognitive ability. In this process, complex spatial relationships and patterns become easy to understand; further more, solving a particular problem in the specific context meets the needs and level of cognitive development of the students. Of course, the above teaching tasks need to be completed with the help, careful guidance and encouragement of teachers.

\section{TEACHING STRATEGY OF CULTIVATING THE STUDENTS' GEO-SPATIAL COGNITIVE ABILITY BY USING REMOTE SENSING}

Through analysis of the aforementioned cases, we can see that remote sensing, as an interpretation and analysis tool, plays an important role in cultivating geographic spatial thinking ability, spatial practical ability of students and the establishment of a regional geographic thinking. In the process of instructional design, geography teachers should give full play to remote sensing's advantages, and create an appropriate teaching environment for the development of students' geospatial cognitive ability. The teaching strategies mainly include the following aspects:

(1) Focus on remote sensing image contrast to explore relationships between geographic elements. Remote sensing image contrast is a comprehensive matter, a contact, reflecting a law of causation. Remote sensing image contrast is helpful in the cultivation of the students' analytical ability regarding geographic spatial relationships. In geography teaching, teachers should stress the use of remote sensing images from different periods and time phases, contrasting the similarities and differences between different spatial phenomena, thus letting the students confirm the contrast process and effect visually, and then explore the spatial relationships between different geographic elements, phenomena and their evolution. Thereby, students can find out reasons for these differences. When learning the chapter on seacoast change, teachers may show remote sensing images of coastal zone from two or more time periods, and compare the process and differences of seacoast change through remote sensing image contrast.

(2) Simulate the spatial reality, and understand geospatial relations. There should be logical relations between different geographic spatial key elements. Through use of remote sensing software systems to simulate the spatial relationships of the real world, one can establish three dimensional analog object images by combining DEM, implementing image scaling and information inquiry, and visualizing attributive information of surface features in spatial distribution. Thus students may acquire a spatial concept about the attributive relationships of geographical things, and carry out coordinate point inquiry as well as area scope inquiry and line inquiry, thereby helping the students establish spatial judgment ability, reasoning and imagination, thus solving geographic spatial problems.

(3) Realize the conversion between $2 \mathrm{D}$ and $3 \mathrm{D}$ images; enhance the mainly two-dimensional expressive force traditional map characterization, which uses abstract symbols to represent complex geographic things and phenomena. This is one of the main reasons that cause perception and understanding difficulty about maps to students. Using remote sensing image processing systems to convert two-dimensional plane images to three-dimensional images can enhance the direct-viewing and visualization of geographic things and phenomena, which is conducive to the students' understanding and application ability about geographic problems. As to terrain, one can use DEM establishment modules, give an elevation value, adjust it to match the remote sensing image, and conduct visualization expression processing on the basis of spatial superimposition. Thus, 3D image of a mountain can be displayed, and you can intuitively observe the mountain peak, mountain valley, mountain ridge, the saddle, cliffs and other terrain and then combine it with maps to carry out study of contour line topographical map interpretation, which will greatly improve teaching efficiency.

(4) Cultivate remote sensing image processing manipulation and software application ability, and develop spatial imagination ability. In geography teaching, teachers shall teach the students to conduct simple treatment on remote sensing data by using remote sensing software operations. Learning through software operation can not only increase the students' ability to use computers, but also exercise their ability to integrate information. In the process of remote sensing image processing, integration is needed to analyze and present multiple source geographic spatial data. In this process, the students' thinking is in a positive state, and learners shall visualize the spatial structure and shape of geographical things in their brains, thereby realizing the conversion between the real geographic things and phenomena and the remote sensing images.

(5) Focus on discerning surface features, and seek the spatial connection between them. When teaching by using remote sensing and the eight key elements of the target surface features in the remote sensing image, the teacher can demand learners to compare the spectral signatures of several different surface features, and get to know and analyze spatial correlations between the essential elements of information of various surface features through the extraction, combination and contrast of various surface feature information. Thereby students can understand the spatial distribution and patterns of these geographical things, and explain causes of distribution characteristics and patterns, thus cultivating their ability to obtain indirect information from remote sensing images.

\section{TEACHING SUGGESTIONS FOR CULTIVATING THE STUDENTS' GEO-SPATIAL COGNITIVE ABILITY BY USING REMOTE SENSING}

First, train geography teachers in remote sensing utilization. Targeted training is the foundation for successful spatial ability cultivation by using remote sensing. Preservice and in-service teachers should receive remote sensing image processing skills training, focusing on the 
training of how to effectively use remote sensing to conduct teaching in the classroom. It is necessary to combine remote sensing use skills and the contents of geography classes. Currently, most remote sensing training programs are mainly teach "about remote sensing", such as operating menus, buttons, tool kits, pan or drag-and-drop, band combinations, output results, etc.. As to how to use remote sensing to conduct effective teaching in class and how to combine remote sensing and the contents of geography classes, there are no effective training programs. As a result, most of the teachers and students can not effectively use remote sensing to cultivate geospatial cognitive ability.

Second, the present remote sensing image processing software versions are designed for expert use, and most of these software packages are not suitable for middle school teachers and students to use directly. Therefore, the user interface should be simplified, and a software system suitable for educational demands of secondary and elementary schools should be further developed. The new system should be simple and easy to learn, flexible and convenient for operation, provide direct feedback, and be designed for middle school students in different age groups, thus making it more attractive.

Third, develop challenging and high-quality classroom learning modes for remote sensing applications. Using remote sensing to cultivate spatial cognitive ability of middle school students needs the support of curriculum, so it needs to develop challenging and high-quality classroom learning modes for remote sensing application. At present, such mode does not exist in the middle school curriculum in China, and researches on it are also rare. Now, although there are powerful remote sensing image processing software and tools supporting spatial ability development such as ERDAS and ENVI, etc., none of those software packages are designed for the geography curriculum or other materials to develop students' geospatial cognitive ability. Therefore, this field needs to develop national spatial cognitive ability standards, and provide middle school teachers and students with the striving direction and evaluation criteria so as to effectively guide the teaching about geo-spatial cognitive ability in the curriculum.

\section{ACKNOWLEDGMENT}

This research was supported by the National Natural Science Foundation of China (No. 41271516).

\section{REFERENCES}

[1] W. Hsaaenpflug, L. Riechelmann, and W. D. John, "Promotion of remote sensing in school education in Germany," IEEE International, vol. 5, pp. 2714-2716, July 1999.

[2] A. N. Ma, "Cognitive approach to remote sensing and geographical information for education," Geography and Geo-Information
Science, vol. 19, pp. 7-11, July 2003 (In Chinese with English abstract).

[3] L. X. Pan, and C L Huang, "Discussion on geographic information technology and high school geography education," China Educational Technology, vol. 2, pp. 90-93, February 2008 (In Chinese).

[4] J. J. Kerski, "The role of GIS in Digital Earth education," International Journal of Digital Earth, vol. 1, pp. 326-346, December 2008. http://dx.doi.org/10.1080/17538940802420879

[5] R. J. Sternberg, Cognitive Psychology, 3rd ed. Beijing: China Light Industry Press, 2006 (In Chinese).

[6] Z. M. Xu, and X. T. Yuan, "Application of GIS in training geospatial abilities of secondary students," China Educational Technology, vol. 8, pp. 96-100, August 2010 (In Chinese).

[7] Ministry of Education of the People's Republic of China, Ordinary High School Geography Curriculum Standard. Beijing: People's Education Press, 2003 (In Chinese).

[8] Z. Q. Mao, L. Zhu, and Z. A. Zhou, New Cartography Curriculum, 2nd ed. Beijing: Higher Education Press, 2008 (In Chinese).

[9] X. Y. Huang, and J. S. Ma, Introduction to GIS, 3rd ed. Beijing: Higher Education Press, 2008 (In Chinese).

[10] H. Haubrich, S. Reinfried, and Y. Schleicher, "Lucerne declaration on geographical education for sustainable development," Acta Geographica Sinica, vol. 63, pp. 219-222, February 2008 (In Chinese).

[11] E. J. Stork, S. O. Sakamoto, and R. M. Cowan, "The intergration of science explorations through the use of Earth images in middle school curriculum," IEEE Transactions on Geoscience and Remote Sensing, vol. 37, pp. 1801-1817, July 1999. http://dx.doi.org/10.1109/36.774693

[12] K. Voss, R. Goetzke, F. Thierfeldt, and G. Menz, "Integrating applied remote sensing methodology in secondary education," IEEE International, pp. 2167-2169, July 2007.

[13] S. Naumann, A. Siegmund, R. Ditter, M. Haspel, M. Jahn, and A. Siegmund, "Remote sensing in school - Theoretical concept and practical implementation," Proceedings of the ISPRS, vol. XXXVIII-6/W7, pp. 17-21, June 2009.

[14] J. C. Luo, and Y. Yang, "Remote sensing intelligentized geoanalysis," Remote Sensing Technology and Application, vol. 15, pp. 199-204, September 2000 (In Chinese with English abstract).

[15] J. Lu, "High school gegraphical teaching based on remote sensing technology," Ordinary High School, vol. 9, pp. 5-8, June 2007 (In Chinese).

[16] P. Peng, X. D. Jiang, X. Y. Wang, and P. Li, "Spatio-temporal changes of land-use in Hefei during the past 19 years," Resource Development \& Market, vol. 24, pp. 18-21, January 2008 (In Chinese with English abstract).

\section{AUTHORS}

L. Wu is with the College of Territorial Resources and Tourism, Anhui Normal University, Wuhu, 241003 China (e-mail: jedi-wuli@163.com; Phone: 15855531081).

H. Y. Liu, is now with the Tongcheng High School, Anhui Province, Tongcheng, 231400 China (e-mail: yezixifeng@sina.com).

P. Peng is with Geological Survey of Anhui Province, Hefei, 230001 China (e-mail: pengp1010@sohu.com).

Submitted 24 November 2013. Published as re-submitted by the authors 09 March 2014 